\title{
Grocery store tour education programme promotes fruit and vegetable consumption
}

\author{
Seung Eun Jung ${ }^{1, *}$, Yeon Ho Shin ${ }^{1}$, Alvin Niuh ${ }^{1}$, Janice Hermann ${ }^{2}$ and \\ Regan Dougherty' \\ 'Department of Human Nutrition and Hospitality Management, The University of Alabama, 486 Russell Hall, Box 87031 1, \\ Tuscaloosa, AL 35487, USA: ${ }^{2}$ Department of Nutritional Sciences, Oklahoma State University, Stillwater, OK, USA
}

Submitted 25 October 2018: Final revision received 4 March 2019: Accepted 2 April 2019: First published online 26 June 2019

\begin{abstract}
Objective: To examine the effectiveness of the Produce for Better Health Foundation grocery store tour programme as a nutrition education tool for changing consumers' intention to consume various forms of fruits and vegetables (F\&V). Design: Cross-sectional study.

Setting: Ten grocery stores in a city in the Southeast USA.

Participants: A total of 147 grocery shoppers in Alabama, who participated in a grocery store tour, completed a retrospective pre-/post-survey using the Theory of Planned Behaviour.

Results: Results from independent-samples $t$ tests indicated that mean values of attitude, subjective norm and perceived control were significantly increased after store tours $(P<0 \cdot 01)$. Participants' intentions to consume various types of F\&V (fresh, dried, canned, juice and frozen), especially dried $F \& V$, increased significantly after store tours. Results from structural equation modelling indicated that before store tours attitude $(\gamma=0.48, P<0.01)$ was the most significant predictor of intention to consume $\mathrm{F} \& \mathrm{~V}$, followed by perceived behavioural control $(\gamma=0 \cdot 24, P=0.02)$ and subjective norm $(\gamma=0.21, P=0.03)$. After store tours, attitude $(\gamma=0.51, P<0.01)$ and perceived behavioural control $(\gamma=0.44, P<0.01)$ were still strong predictors of intention to consume $\mathrm{F} \& \mathrm{~V}$, while subjective norm became an insignificant predictor of intention.

Conclusions: Findings revealed positive changes in study participants' attitude, subjective norm, perceived behavioural control and their intentions to consume various forms of $\mathrm{F} \& \mathrm{~V}$, which suggest potential benefits of providing grocery store tours as a tool to promote consumers' F\&V intake.
\end{abstract}

In 2010, over half of Americans suffered from at least one chronic condition and nearly one-third of all Americans suffered from multiple chronic conditions. Chronic conditions can decrease an individual's quality of life and generate a significant economic burden. Medical care for Americans with multiple chronic conditions accounts for approximately $71 \%$ of total health-care spending in the USA each year ${ }^{(1)}$. Due to the positive health outcomes associated with fruit and vegetable (F\&V) consumption, including prevention of chronic disease ${ }^{(2)}$, it is in the interest of health professionals and public officials to promote F\&V consumption among the general population. Unfortunately, only about $9 \%$ of Americans meet the recommended intake of vegetables and only $12 \%$ meet the recommended intake of fruits ${ }^{(3)}$.
Grocery stores are an ideal place to provide nutrition education targeted at increasing consumers' F\&V intake. In 2017, Americans made an average of 1.5 trips to the grocery store each week $^{(4)}$. Additionally, in 2014, a significant majority (approximately $86 \%$ ) of US consumers named grocery stores and supermarkets as their primary shopping location for food $^{(5)}$. Specifically, nutrition education through grocery store tours provides a unique learning environment that allows consumers to learn in a real-life setting ${ }^{(6)}$. Previous findings indicate that consumers who participated in grocery store tours had increased nutrition knowledge $\mathrm{e}^{(7-9)}$, increased intention to purchase healthy foods ${ }^{(7-9)}$, improved attitudes towards healthy foods ${ }^{(7)}$, increased self-efficacy to purchase healthy foods ${ }^{(7)}$ and adopted positive behaviour changes ${ }^{(7,9-11)}$. Although many grocery store tour 
programmes exist, such as the US Department of Agriculture Supplemental Nutrition Assistance Program Education ${ }^{(12)}$, the Linus Pauling Institute Grocery Store Tour programme by Oregon State University ${ }^{(13)}$ and the American Heart Association's Healthy for Life Educational experience programme ${ }^{(14)}$, these programmes focus on promoting a variety of food groups. The Produce for Better Health (PBH) Foundation's grocery store education programme is unique in that it is solely aimed at promoting the consumption of F\&V, which is why this programme was utilized in the present study ${ }^{(15)}$.

The $\mathrm{PBH}$ grocery store education programme was developed specifically for administration by dietetics students. It encourages consumption of all forms of $\mathrm{F} \& \mathrm{~V}$, including fresh, canned, frozen and dried. The programme includes emphasis of each form, followed by interactive components to enhance learning. Key messages of the tour include: increasing F\&V consumption, increasing variety of $\mathrm{F} \& \mathrm{~V}$ consumed and making half of your plate filled with $F \& V$. In a prior study evaluating the effectiveness of the PBH grocery store tour education programme, college students enrolled in an introductory nutrition class benefited from the tours. Following the tour, $69 \%$ of the students noted that they would definitely consume more $F \& V^{(15)}$.

While existing studies show promise for grocery store interventions as a means of increasing nutrition knowledge and changing diet-related behaviours ${ }^{(6,16,17)}$, there is limited theory-based research evaluating the effectiveness of grocery store interventions on consumers' intention to consume $F \& V^{(6)}$.

The Theory of Planned Behaviour (TPB) is based on the concept that an individual's intention to partake in a particular behaviour depends on his/her attitude, subjective norm and perceived behavioural control ${ }^{(18)}$. Attitude refers to an individual's evaluation (e.g. favourable or unfavourable) of a particular behaviour. Subjective norm is perceived social pressure regarding the behaviour. Perceived behavioural control is the degree of control an individual feels he/she has with regard to the behaviour ${ }^{(18)}$. The TPB has been identified as an effective framework to predict intentions and behaviours with regard to food choices and nutrition-related behaviours, including F\&V consumption $^{(19,20)}$. Therefore, the present study used the TPB as the framework to investigate the impact of the $\mathrm{PBH}$ grocery store tour education programme on promoting F\&V consumption among grocery shoppers.

Specific objectives were as follows:

1. To measure the impact of the grocery store tour education programme on consumers' attitude, subjective norm, perceived behavioural control related to F\&V and consumers' intention to consume different types of $F \& V$.

2. To measure the relationship of consumers' attitude, subjective norm and perceived behavioural control with intention to eat $\mathrm{F} \& \mathrm{~V}$, and identify the best predictors of intention to eat $\mathrm{F} \& \mathrm{~V}$.
3. To investigate how the grocery store tour education programme changed the relationship between consumers' attitude, subjective norm and perceived behavioural control and intention to eat F\&V.

\section{Methods}

\section{Participants}

Data for the present study were collected through a selfadministered survey of grocery shoppers, aged 18 years or older, in a city in the Southeast USA using convenience sampling. Students from a Service Learning class were selected to be research assistants and were trained to conduct the grocery store tour. The student research assistants were divided into ten teams and each team was then assigned to a grocery store. The teams were trained using the $\mathrm{PBH}$ grocery store education programme training kit. In addition, the teams viewed several grocery store tour videos readily available online, then discussions were held to address the strong points that could be adopted and the mistakes to avoid. Each team visited its assigned grocery store to familiarize research assistants with the layout of the store and the location of various types of $\mathrm{F} \& \mathrm{~V}$ products. Each team was also required to develop a script that was appropriate to each store and the products available, and to incorporate the material provided by $\mathrm{PBH}$. Before the first grocery tour was conducted, the teams created and posted advertising flyers to promote the grocery store tour at each store. After training, the research assistants went to ten different local grocery stores to conduct the PBH grocery store tour education programme. A table was set up, either at the entrance of the store or near the fresh produce area, to recruit participants at each grocery store. The research assistants provided the grocery store tour education programme to people who were interested in participating, following the established script to ensure that all key and relevant points were presented to the participants. Both individual and group tours were conducted. Selection was based on the number of interested participants at the time the tour was offered. Group size was limited to five individuals per tour. At the conclusion of each tour, participants were given the opportunity to ask additional questions before the research assistant presented the participants with the opportunity to complete a voluntary retrospective pre-/post-survey measuring TPB constructs. Small incentives were provided to all tour participants but no additional compensation was provided for completing the survey. As a result, a total of 147 usable surveys were collected.

\section{Measurement items}

Validated and reliable TPB measurement items developed in previous research were adapted for the current study $^{(18,21,22)}$. The adapted survey was also reviewed by three experts for content validity. Attitude was measured 
with four items (disadvantageous-advantageous; foolishwise; unpleasant-pleasant; unattractive-attractive) using a 7-point bipolar scale. Subjective norm was measured with three items, which were 'Most people who are important to me would want me to eat F\&V', 'It is expected of me that I eat F\&V' and 'I feel that the important people in my life want me to eat F\&V'. Perceived behavioural control was measured with three items, which included 'The decision to consume $\mathrm{F} \& \mathrm{~V}$ is in my control', 'Whether I consume $\mathrm{F} \& \mathrm{~V}$ is entirely up to me' and 'If I wanted to, I could easily eat $F \& V$ '. Intention to eat $F \& V$ was conducted for six categories of F\&V (in general, fresh, dried, canned, juice and frozen). Intention for each category was measured with three items. Sample items for dried F\&V included 'I am planning to eat dried F\&V', 'I intend to eat dried F\&V' and 'I will expend effort on eating dried F\&V'. Subjective norm, perceived behavioural control and intention items were measured using a 7-point Likert scale from 'strongly disagree' $(=1)$ to 'strongly agree' $(=7)$.

\section{Data analysis}

Descriptive statistics were conducted to analyse demographic information such as age, gender, race and marital status. Paired-samples $t$ tests were used to determine if differences existed between pre- and post-intervention by comparing mean scores of attitude, subjective norm, perceived behavioural control and intention. To measure the relationship between attitude, subjective norm, perceived behavioural control and intention to eat F\&V and to investigate the effect of the intervention, structural equation modelling (SEM) using two separate models with the maximum likelihood estimation method was conducted on the preand post-intervention data. SEM was chosen over other analytic approaches such as multiple regression due to its ability to correct measurement errors ${ }^{(23-26)}$. Based on the TPB, attitude, subjective norm and perceived control were entered as exogenous variables while intention was entered as an endogenous variable in both models. As Anderson and Gerbing recommended ${ }^{(27)}$, the measurement model was evaluated and respecified using a confirmatory factor analysis first before proceeding to SEM. Validity and reliability were checked using Cronbach's $\alpha$, average variance extracted and maximum shared variance. The goodness-of-fit of the models was evaluated using: (i) the $\chi^{2}$ goodness-of-fit statistic; (ii) the root-mean-square error of approximation (RMSEA); (iii) the comparative fit index (CFI); and (iv) Tucker-Lewis index (TLI). IBM SPSS Statistics version 24.0 and Mplus 7 were used as statistical tools.

\section{Results}

\section{Demographic information}

A total of 147 shoppers from ten different grocery stores participated in the survey. As shown in Table 1, 48.9\% of
Table 1 Demographic characteristics of 147 grocery shoppers from ten grocery stores who participated in the grocery store tour education programme, Southeast USA, February-May 2017

\begin{tabular}{|c|c|}
\hline Variable & $\%$ \\
\hline \multicolumn{2}{|l|}{ Age } \\
\hline 18-24 years & 48.9 \\
\hline $25-34$ years & 11.5 \\
\hline $35-44$ years & $12 \cdot 2$ \\
\hline $45-54$ years & 9.4 \\
\hline $55-64$ years & $10 \cdot 1$ \\
\hline 65 years or older & 7.9 \\
\hline \multicolumn{2}{|l|}{ Gender } \\
\hline Male & $21 \cdot 1$ \\
\hline Female & 73.5 \\
\hline \multicolumn{2}{|l|}{ Race } \\
\hline Caucasian & $57 \cdot 1$ \\
\hline African American & $22 \cdot 4$ \\
\hline Native American & 1.4 \\
\hline Hispanic or Latino & $2 \cdot 0$ \\
\hline Asian & 1.4 \\
\hline Other or no answer & $15 \cdot 7$ \\
\hline \multicolumn{2}{|l|}{ Marital status } \\
\hline Single & $55 \cdot 1$ \\
\hline Married & $30 \cdot 6$ \\
\hline Other or no answer & $14 \cdot 3$ \\
\hline \multicolumn{2}{|l|}{ Education } \\
\hline Less than high school & 0.8 \\
\hline High-school diploma & $15 \cdot 0$ \\
\hline Some college & $45 \cdot 7$ \\
\hline Associate degree & $6 \cdot 3$ \\
\hline Bachelor's degree & $25 \cdot 2$ \\
\hline Graduate degree & $7 \cdot 1$ \\
\hline
\end{tabular}

participants were aged 18-24 years, followed by 35-44 years (12.2\%), 25-34 years (11.5\%), 55-64 years (10.1\%), $45-54$ years $(9.4 \%)$ and 65 years or above $(7.9 \%)$. The majority of participants were female $(73.5 \%)$ and Caucasian $(57 \cdot 1 \%)$. In terms of marital status, $55.1 \%$ of participants were single and $30.6 \%$ were married. Regarding education, approximately $40 \%$ had an associate degree or above.

\section{Paired-samples $t$ tests}

The first research objective was to identify the effectiveness of the grocery store tour education programme by comparing pre- and post-intervention attitude, subjective norm, perceived behavioural control and intention to eat various types of $\mathrm{F} \& \mathrm{~V}$. A paired-samples $t$ test was conducted to compare mean differences between pre- and postintervention on attitude, subjective norm and perceived behavioural control. As shown in Table 2, mean values for attitude, subjective norm and perceived control were increased significantly after the intervention $(P<0 \cdot 01)$.

Another paired-samples $t$ test was carried out to investigate the effect of the intervention on increasing participants' intention to eat different forms of F\&V $(P<0.01)$. Significant increases were observed in participants' intention to eat F\&V in general (before: $5 \cdot 41$, after: $6 \cdot 14, P<0 \cdot 01$; Table 3 ) as well as to eat different forms of F\&V (fresh, dry, canned, juice and frozen; Table 3). Among the intentions to eat 
Table 2 Paired-samples $t$ test: attitude, subjective norm and perceived behavioural control regarding the consumption of fruits and vegetables among 147 grocery shoppers from ten grocery stores before and after participating in the grocery store tour education programme, Southeast USA, February-May 2017

\begin{tabular}{|c|c|c|c|c|c|}
\hline & \multicolumn{2}{|c|}{ Meant } & \multirow[b]{2}{*}{ Difference (after-before) } & \multirow[b]{2}{*}{$t$ value } & \multirow[b]{2}{*}{ Significance (two-tailed $P$ value) } \\
\hline & Before & After & & & \\
\hline Attitude & $5 \cdot 84$ & $6 \cdot 42$ & 0.58 & 8.23 & $<0.01$ \\
\hline Subjective norm & $5 \cdot 60$ & $6 \cdot 14$ & 0.54 & 8.38 & $<0.01$ \\
\hline Perceived behavioural control & $5 \cdot 81$ & $6 \cdot 25$ & 0.44 & $6 \cdot 73$ & $<0.01$ \\
\hline
\end{tabular}

†Attitude, subjective norm and perceived behavioural control were measured on bipolar and Likert scales ranging from 1 to 7 (with higher mean values indicating more positive attitude, subjective norm and perceived behavioural control).

Table 3 Paired-samples $t$ test: intention to consume fruits and vegetables (in general, fresh, dried, canned, juice and frozen) among 147 grocery shoppers from ten grocery stores before and after participating in the grocery store tour education programme, Southeast USA, February-May 2017

\begin{tabular}{lccccc}
\hline & \multicolumn{2}{c}{ Meant } & & & \\
\cline { 2 - 5 } & Before & After & Difference (after-before) & $t$ value & Significance (two-tailed $P$ value) \\
\hline Intention (Overall) & 5.41 & 6.14 & 0.73 & 7.98 & $<0.01$ \\
Intention (Fresh) & 5.45 & 6.11 & 0.66 & 6.53 & $<0.01$ \\
Intention (Dry) & 4.12 & 5.09 & 0.97 & 7.43 & $<0.01$ \\
Intention (Canned) & 4.30 & 5.15 & 0.85 & 8.18 & $<0.01$ \\
Intention (Juice) & 4.73 & 5.62 & 0.89 & 8.31 & $<0.01$ \\
Intention (Frozen) & 4.84 & 5.77 & 0.93 & 8.86 & $<0.01$ \\
\hline
\end{tabular}

†Intentions were measured on Likert scales ranging from 1 to 7 (with higher mean values indicating more intention).

Table 4 Validity analysis for the measurement model (preintervention)

\begin{tabular}{lccc}
\hline & CR & AVE & MSV \\
\hline Attitude & 0.93 & 0.87 & 0.59 \\
Subjective norm & 0.93 & 0.87 & 0.47 \\
Perceived behavioural control & 0.91 & 0.77 & 0.47 \\
Intention & 0.95 & 0.86 & 0.50
\end{tabular}

$\mathrm{CR}$, composite reliability; AVE, average variance extracted; MSV, maximum shared variance.

Table 5 Validity analysis for the measurement model (postintervention)

\begin{tabular}{lccc}
\hline & CR & AVE & MSV \\
\hline Attitude & 0.79 & 0.66 & 0.61 \\
Subjective norm & 0.94 & 0.83 & 0.61 \\
Perceived behavioural control & 0.89 & 0.73 & 0.53 \\
Intention & 0.92 & 0.79 & 0.55
\end{tabular}

CR, composite reliability; AVE, average variance extracted; MSV, maximum shared variance.

various type of $F \& V$, the greatest mean increase between pre- and post-intervention was in participants' intention to eat dried F\&V (before: 4.12, after: 5.09, $P<0 \cdot 01$ ).

\section{Structural equation modelling}

Before proceeding to SEM, the measurement model was accessed using confirmatory factor analysis with maximum likelihood estimation for both data sets (pre- and postintervention) ${ }^{(27)}$. Based on the results, two items (attitude: disadvantageous-advantageous, subjective norm: 'People whose opinions I value would prefer me to eat F\&V') from preintervention data and one item (attitude: unpleasant-pleasant) from post-intervention data were dropped due to their low factor loadings and low squared multiple correlations ${ }^{(28)}$. After deletion, confirmatory factor analyses were reconducted. Cronbach's $\alpha$ ranged from 0.78 to 0.94 for all four constructs in both data sets, exceeding the suggested cut-off value of $0.70^{(29)}$. All standardized factor loadings were between 0.75 and 0.95 , meeting the minimum criterion of $0.50^{(28)}$. The squared multiple correlations were at least $0 \cdot 56$, demonstrating adequate reliability levels ${ }^{(28)}$. Convergent validity was confirmed since all average variance extracted values exceeded 0.50 and composite reliability values were at least 0.79 (Tables 4 and 5) ${ }^{(30)}$. All maximum shared variance values were less than the associated average variance extracted values, indicating discriminant validity was satisfied (Tables 4 and 5$)^{(30)}$. The measurement models analysed with the preintervention data had overall adequate model fit statistics, indicating the measurement model provides a good fit to the data $\left(\chi^{2}=61.90, \quad \mathrm{df}=29 \quad(P<0.01) ; \quad \mathrm{RMSEA}=0.08, \quad \mathrm{CFI}=0.98\right.$, TLI $=0.95)$. However, the RMSEA for the measurement model analysed using post-intervention data had only a mediocre overall fit due to its RMSEA value being slightly higher than $0.08 \quad\left(\chi^{2}=91.63, \quad \mathrm{df}=38 \quad(P<0.01) ; \quad\right.$ RMSEA $=0.09$, $\mathrm{CFI}=0.96, \mathrm{TLI}=0.92)^{(31,32)}$.

After evaluating the measurement models, SEM was conducted to examine the relationships among the constructs in each sample. The structural model analysed with pre-intervention data provided a good fit to the data 

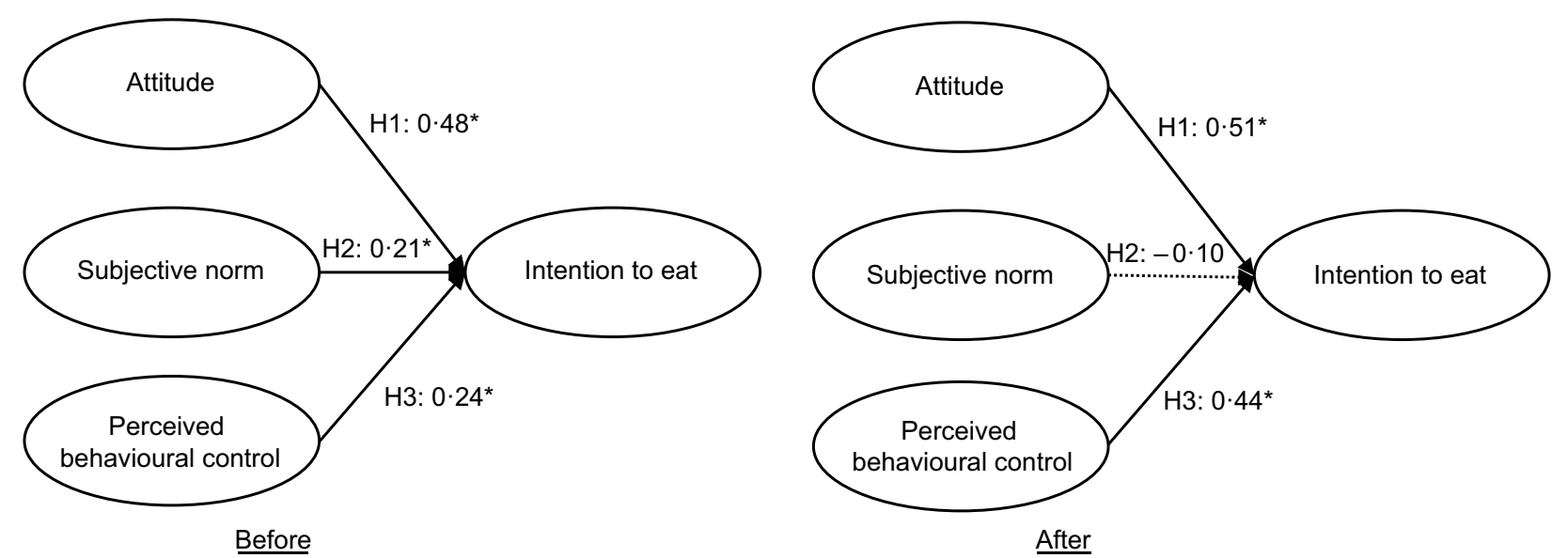

Fig. 1 Structural relationship among the Theory of Planned Behaviour constructs - attitude, subjective norm, perceived behavioural control and intention (to eat fruits and vegetables $(F \& V)$ ) - among 147 grocery shoppers from ten grocery stores before and after participating in the grocery store tour education programme, Southeast USA, February-May 2017. ${ }^{\star} P<0.05$ (H1, attitude will be significantly associated with intention to eat $\mathrm{F} \& \mathrm{~V} ; \mathrm{H} 2$, subjective norm will be significantly associated with intention to eat $\mathrm{F} \& \mathrm{~V}$; $\mathrm{H} 3$, perceived behavioural control will be significantly associated with intention to eat $F \& V$ )

$\left(\chi^{2}=61 \cdot 90, \mathrm{df}=29(P<0 \cdot 01) ; \mathrm{RMSEA}=0 \cdot 08, \mathrm{CFI}=0.98\right.$, TLI $=0.95)$, while the structural model analysed with postintervention data provided a mediocre fit to the data $\left(\chi^{2}=91.63, \mathrm{df}=38(P<0.01) ; \mathrm{RMSEA}=0.09, \mathrm{CFI}=0.96\right.$, TLI $=0.92)$. As shown in Fig. 1 , the results from preintervention data indicated that attitude $(\gamma=0.48, P<0 \cdot 01)$ was the most significant predictor of intention to eat $\mathrm{F} \& \mathrm{~V}$, followed by perceived behavioural control $(\gamma=0.24$, $P=0.02)$ and subjective norm $(\gamma=0.21, \quad P=0.03)$. However, the relationship between subjective norm and intention to eat F\&V became insignificant in the structural model analysed with post-intervention data. In addition, the effect size of perceived behavioural control on intention became larger $(\gamma=0.24, P=0.02 \rightarrow \gamma=0.44, P<0.01)$. Attitude was still the strongest predictor of intention $(\gamma=0.51, P<0.01)$, followed by perceived behavioural control $(\gamma=0.44, P<0.01)$. Overall, the proposed model analysed using pre-intervention data explained $61 \%$ of the variance in intention (squared multiple correlation $=0.61$ ) while the model analysed with post-intervention data explained $63 \%$ of the variance in intention (squared multiple correlation $=0.63$ ).

\section{Discussion}

Following the grocery store intervention, participants' attitudes, subjective norm, perceived behavioural control and intentions regarding the consumption of F\&V increased significantly. According to Ajzen ${ }^{(18)}$, attitude, subjective norm and perceived behavioural control shape an intention to perform a behaviour. When attitude, subjective norm and perceived behavioural control are favourable, an individual is more likely to have intention to perform a given behaviour. Thus, the grocery store tour education programme was effective at changing attitude, subjective norm and perceived behavioural control in a positive way. These results are consistent with previous studies that have shown positive outcomes following grocery store tours. For example, a grocery store intervention facilitated by peer leaders resulted in an increased participant use of nutrition labels while selecting foods for purchase at the grocery store ${ }^{(7)}$. In addition, a significant increase in $n$-3-rich food purchases was observed with point-of-purchase nutrition education using podcasts as a grocery store tour ${ }^{(33)}$. Milliron et al. also reported grocery store intervention at the point of purchase successfully assisted consumers in purchasing healthier food items, such as $F \& V^{(34)}$. These positive effects of grocery store interventions could be contributed to the additional nutrition knowledge provided to consumers. Prior to these interventions, consumers may not have adequate nutrition knowledge to make healthy food choices ${ }^{(35)}$. Providing education in a real-life setting, at the point of purchase, may enhance the learning experience of consumers and promote positive behaviours. Furthermore, McGee and colleagues reported that knowledge of the risks and benefits of food choices motivated focus group participants to make healthy choices at the grocery store ${ }^{(36)}$. Therefore, grocery store tours should be considered an effective tool for changing individuals' beliefs and intentions regarding the consumption of healthy food items, including F\&V.

Although the intention to consume dried F\&V was still lower than for other forms of F\&V following the intervention, the increase in intention to consume dried F\&V was significantly greater than for other forms. This result could be due to the fact that tour participants were not aware dried F\&V were a good option for increasing F\&V intake. In fact, a previous study suggests consumption of dried fruit is associated with decreased incidence of chronic diseases such as obesity, type 2 diabetes, CVD and certain types of cancer $^{(37)}$. A review by Morais et al. revealed dried F\&V have similar beneficial components to fresh F\&V, including 
antioxidants $^{(37-44)}$ and resistant starches ${ }^{(37,45)}$. Polyphenols and tocopherols found in dried F\&V have been found to be readily available for absorption in the body ${ }^{(37,46,47)}$. Depending on the processing technique, dried F\&V can retain a large percentage of the nutrients that are available in the fresh product. For example, over $84 \%$ of the carotenoid content of fresh carrots can be preserved in dried car$\operatorname{rots}^{(37,48)}$. Up to $92 \%$ of the lycopene in tomatoes can be preserved in the drying process ${ }^{(37,49)}$. In some instances, the antioxidant capacity of F\&V may even be increased during the drying process due to reactions that occur ${ }^{(37,38)}$. In fact, the antioxidant activity in dried cranberries, grapes and plums can be twice as high as in the fresh fruit ${ }^{(37,50)}$.

Another major benefit of dried $\mathrm{F} \& \mathrm{~V}$ is their increased shelf-life compared with fresh $F \& V^{(37)}$. This increased shelf-life has positive implications for individuals with limited access to food. Additionally, the 2015-2020 Dietary Guidelines for Americans assert that all forms of $F \& V$, including dried $\mathrm{F} \& \mathrm{~V}$, fit into a healthy eating pattern ${ }^{(51)}$. Given the benefits of dried $F \& V$, in terms of both health and shelf-stability, it is recommended that grocery store tour curricula include dried $\mathrm{F} \& \mathrm{~V}$ as an effective means of increasing F\&V intake.

Participants' attitude was the most significant predictor of their intention to consume F\&V both before and after the grocery store intervention. This finding is consistent with previous studies that also found attitude to be a significant predictor of intention to participate in various foodrelated behaviours ${ }^{(52-54)}$. Prior research has indicated that knowledge of the health benefits of a particular food or food group is associated with a positive attitude towards the food ${ }^{(55)}$. A study by Rah and colleagues also found favourable taste resulted in a positive attitude towards soya products ${ }^{(56)}$. Thus, incorporating nutrition education and food samples into a grocery store intervention may be effective ways to improve attitude.

Perceived behavioural control also played a significant role in predicting the study participants' intention to consume F\&V both before and after the grocery store intervention. A number of previous studies have found perceived behavioural control to be a significant predictor of intention to partake in a variety of dietary practices, including consumption of $F \& V^{(53,57)}$ and dairy products ${ }^{(54)}$. Commonly cited barriers to $\mathrm{F} \& \mathrm{~V}$ consumption include cost, cooking time, convenience of packaged foods and short shelf-life of $\mathrm{F} \& \mathrm{~V}^{(58)}$. Addressing key strategies to overcome these barriers in grocery store tour curricula could potentially increase grocery store shoppers' self-efficacy in choosing F\&V. For example, a nutrition education programme that included a cooking component and provided recipes to participants was shown to increase self-efficacy and confidence in planning and preparing healthy meals ${ }^{(59)}$.In addition, an online nutrition education programme that included cooking demonstration videos resulted in increased perceptions of the 'ease of cooking healthy foods ${ }^{(60)}$. Therefore, incorporating cooking demonstrations and recipes into grocery store tour curricula could result in heightened feelings of control and increased intention. To address the perceived barrier of fresh F\&V's short shelf-life, educators would need to remind participants of the benefits of non-fresh forms of F\&V.

Subjective norm was found to be a significant predictor of intention prior to the grocery intervention. Therefore, reaching out to not only the target audience but also their referent people, such as their friends and family members, would be a good strategy for effective nutrition education. Although subjective norm was a significant predictor prior to the grocery store intervention, it was not a significant predictor post-intervention. Other previous studies have also found subjective norm to be an insignificant predictor of intention to consume $F \& \mathrm{~V}^{(53,61)}$. It is possible that subjective norm is no longer as influential on intentions once knowledge and confidence are gained and individuals can depend on their own decision-making abilities ${ }^{(54)}$. After participating in the grocery store intervention, study participants had improved attitudes and perceived behavioural control regarding $\mathrm{F} \& \mathrm{~V}$ consumption and may no longer have felt the need for their dietary behaviours to be validated by friends and family.

\section{Limitations}

There are several limitations to the present study. First, it was conducted in a city in the Southeast USA, which limits the generalizability of the findings. A second limitation is the relatively small sample size despite being adequate for SEM analyses ${ }^{(62,63)}$. Moreover, convenience sampling may have influenced the study results. For example, the majority of participants were 18 to 24 years of age, Caucasian and female, and thus are not representative of the general population. Therefore, more research with larger and random samples would be necessary to generalize the findings. Lastly, although the present study identified significant predictors of grocery shoppers' intention to consume F\&V, participants' actual F\&V intake was not measured. Therefore, future research measuring actual $\mathrm{F} \& \mathrm{~V}$ consumption is needed to determine if grocery store interventions increase actual intake of F\&V. Such studies should examine the relationships between $F \& V$ intake and TPB variables.

\section{Conclusions}

Given the high rate of chronic conditions in the USA and the shockingly low rates of $\mathrm{F} \& \mathrm{~V}$ consumption, despite well-established health benefits, novel interventions to increase F\&V consumption are warranted. Grocery stores provide a unique learning environment and grocery store interventions should be considered as a potential means to increase $\mathrm{F} \& \mathrm{~V}$ consumption among the general population. The present study found a grocery store intervention focusing on F\&V consumption has the ability to improve attitudes, subjective norm, perceived behavioural control and intention to eat F\&V. Interestingly, the present study found participants' intentions to eat dried F\&V increased significantly more than 
intentions to eat F\&V in general. Due to the health and economic benefits of dried $\mathrm{F} \& \mathrm{~V}$, grocery store interventions should promote consumption of $\mathrm{F} \& \mathrm{~V}$ in this form. Participants' attitudes and perceived behavioural control were both significant predictors of intention to eat F\&V both before and after the intervention. However, subjective norm was not a significant predictor of intention to eat F\&V following the intervention. It is possible that subjective norm loses its influence on intentions once attitudes and perceived behavioural control improve and individuals feel that they are capable of making their own decisions.

The study supports previous research findings that attitude and perceived behavioural control are both significant predictors of intention to partake in a variety of health and nutrition-related behaviours. Due to these findings, further research is warranted to investigate effective mechanisms to improve attitude and perceived behavioural control. This, in turn, will provide guidance in improving grocery store interventions and other nutrition intervention programmes.

\section{Acknowledgements}

Acknowledgements: The authors thank the local grocery stores who allowed them to conduct the project in their spaces and the University of Alabama nutrition students who led the grocery store tours. Financial support: This project was funded by the Produce for Better Health ( $\mathrm{PBH}$ ) Foundation's grocery store education grant. The PBH Foundation had no role in the design, analysis or writing of this article. Conflict of interest: No authors report conflict of interest. Authorship: S.E.J. and Y.H.S. designed the study and analysed the data. A.N. collected the data. All authors (S.E.J., Y.H.S., A.N., J.H. and R.D.) contributed to the writing, interpretation of the data and editing the manuscript critically for important intellectual content. Ethics of human subjectparticipation: This study was conducted according to the guidelines laid down in the Declaration of Helsinki and all procedures involving human subjects were approved by the University of Alabama Human Research Ethics Committee. Written informed consent was obtained from all subjects.

\section{References}

1. Gerteis J, Izrael D, Deitz D et al. (2014) Multiple Chronic Conditions Chartbook. AHRQ Publication no. Q14-0038. Rockville, MD: Agency for Healthcare Research and Quality.

2. Boeing H, Bechthold A, Bub A et al. (2012) Critical review: vegetables and fruit in the prevention of chronic diseases. Eur J Nutr 51, 637-663.

3. Lee-Kwan SH, Moore LV, Blanck HM et al. (2017) Disparities in state-specific adult fruit and vegetable consumption United States, 2015. MMWR Morb Mortal Wkly Rep 66, 1241-1247.
4. Food Marketing Institute (2017) US grocery shopper trends 2017. https://www.fmi.org/docs/default-source/documentshare/fmi-grocery-trends-2017-final-pdf-06-07-17.pdf?sfvrsn= 2294716e_2 (accessed September 2018).

5. Food Marketing Institute (2014) US grocery shopping trends 2014. https://www.fmi.org/docs/default-source/research/ presentation.pdf?sfvrsn $=0$ (accessed September 2018).

6. Nikolaus CJ, Muzaffar H \& Nickols-Richardson SM (2016) Grocery store (or supermarket) tours as an effective nutrition education medium: a systematic review. J Nutr Educ Behav 48, 544-554.

7. Carson JAS \& Hedl JJ (1998) Smart shopper's tours: outcome evaluation. J Nutr Educ 30, 323-331.

8. Lafferty A, Marquart L \& Reicks M (2006) Hunting for whole grains: a supermarket tour. J Nutr Educ Behav 38, 197-198.

9. van Assema P, Cremers S \& van Dis I (1996) Nutrition education tours in the supermarket: the results of a pilot project in the Netherlands. In Multidisciplinary Approaches to Food Choice, pp. 174-178 [A Worsley, editor]. Adelaide: Food Choice Conference.

10. Baic S \& Thompson JL (2007) Prevent it: using grocery store tours as an educational tool to promote heart health. ACSMs Health Fit J 11, 15-20.

11. Slizer JS, Sheeska J, Tomasik HH et al. (1994) An evaluation of Supermarket Safari nutrition education tours. J Can Diet Assoc 55, 179-183.

12. US Department of Agriculture (2018) Supplemental Nutrition Assistance Program Education (SNAP-Ed). https://www.fns. usda.gov/snap/supplemental-nutrition-assistance-programeducation-snap-ed (accessed September 2018).

13. Healthy Youth Program, Linus Pauling Institute, Oregon State University (2014) Grocery Store Tours Program Manual. https://lpi.oregonstate.edu/sites/lpi.oregonstate.edu/files/ pdf/hyp/lessons-manuals/grocery_store_tours_manual.pdf (accessed September 2018).

14. Aramark \& American Heart Association (2017) Healthy for Life Education Experiences. Facilitator Guide. http://www. heart.org/idc/groups/heart-public/@wcm/@fc/documents/ downloadable/ucm_492042.pdf (accessed September 2018).

15. Thompson KL, Silver C, Pivonka E et al. (2015) Fruit- and vegetable-focused grocery store training kit to promote peer-on-peer nutrition education utilizing nutrition and dietetics students. J Nutr Educ Behav 47, 472-476.

16. Escaron AL, Meinen AM, Nitzke SA et al. (2013) Supermarket and grocery store-based interventions to promote healthful food choices and eating practices: a systematic review. Prev Chronic Dis 10, E50.

17. Liberato SC, Bailie R \& Brimblecombe J (2014) Nutrition interventions at point-of-sale to encourage healthier food purchasing: a systematic review. BMC Public Health 14, 919.

18. Ajzen I (1991) The Theory of Planned Behavior. Organ Behav Hum Decis Process 50, 179-211.

19. Armitage CJ \& Conner M (2001) Efficacy of the theory of planned behaviour: a meta-analytic review. $\mathrm{Br} J \mathrm{Soc}$ Psychol 40, 471-499.

20. Hardeman W, Johnston M, Johnston D, et al. (2002) Application of the theory of planned behaviour in behaviour change interventions: a systematic review. Psychol Health 17, 123-158.

21. Francis J, Eccles MP, Johnston M et al. (2004) Constructing Questionnaires based on the Theory of Planned Behaviour: A Manual for Health Services Researchers. Newcastle upon Tyne: Centre for Health Services Research, University of Newcastle upon Tyne.

22. Shin YH, Hancer M \& Song JH (2016) Self-congruity and the Theory of Planned Behavior in the prediction of local food purchase. J Int Food Agribus Mark 28, 330-345.

23. Nunkoo R \& Ramkissoon H (2012) Structural equation modelling and regression analysis in tourism research. Curr Issues Tour 15, 777-802. 
24. Musil CM, Jones SL \& Warner CD (1998) Structural equation modeling and its relationship to multiple regression and factor analysis. Res Nurs Health 21, 271-281.

25. Schreiber JB, Nora A, Stage FK et al. (2006) Reporting structural equation modeling and confirmatory factor analysis results: a review. J Educ Res 99, 323-338.

26. Kline R (2010) Principles and Practice of Structural Equation Modeling. New York: Guilford Press.

27. Anderson JC \& Gerbing DW (1988) Structural equation modeling in practice: a review and recommended two-step approach. Psychol Bull 103, 411-423.

28. Hair JF, Black WC, Babin BJ et al. (2006) Multivariate Data Analysis, 6th ed. Upper Saddle River, NJ: Pearson Prentice Hall.

29. Nunnally JC \& Bernstein I (1994) Psychometric Theory, 3rd ed. New York: McGraw-Hill.

30. Fornell C \& Larcker DF (1981) Evaluating structural equation models with unobservable variables and measurement error. J Mark Res 18, 39-50.

31. Byrne B (2001) Structural Equation Modeling with AMOS: Basic Concepts, Applications, and Programming. New York: Taylor \& Francis Group.

32. MacCallum RC, Browne MW \& Sugawara HM (1996) Power analysis and determination of sample size for covariance structure modeling. Psychol Methods 1, 130-149.

33. Bangia D, Shaffner DW \& Palmer-Keenan DM (2017) A pointof-purchase intervention using grocery store tour podcasts about omega-3s increases long-term purchases of omega3-rich food items. J Nutr Educ Behav 49, 475-480.

34. Milliron BJ, Woolf K \& Appelhans BM (2012) A point-ofpurchase intervention featuring in-person supermarket education affects healthful food purchases. J Nutr Educ Behav 44, 225-232.

35. Sonnenberg L, Gelsomin E, Levy DE et al. (2013) A traffic light food labeling intervention increases consumer awareness of health and healthy choices at the point-of-purchase. Prev Med 57, 253-257.

36. McGee BB, Johnson GS, Yadrick MK et al. (2011) Food shopping perceptions, behaviors, and ability to purchase healthful food items in the lower Mississippi delta. J Nutr Educ Behav 43, 339-348.

37. Morais RMSC, Morais AMMB, Dammak I et al. (2018) Functional dehydrated foods for health preservation. J Food Qual 41, 1739636.

38. Yilmaz Y \& Toledo R (2005) Antioxidant activity of watersoluble Maillard reaction products. Food Chem 93, 273-278.

39. Mirmiran P, Noori N, Zavareh MB et al. (2009) Fruit and vegetable consumption and risk factors for cardiovascular disease. Metab Clin Exp 58, 460-468.

40. Gomez M \& Martinez MM (2017) Fruit and vegetable by-products as novel ingredients to improve the nutritional quality of baked goods. Crit Rev Food Sci Nutr 58, 2119-2135.

41. Meydani M \& Azzi A (2017) Dietary antioxidants and bioflavonoids in atherosclerosis and angiogenesis. In Nutrigenomics and Proteomics in Health and Disease: Towards a System-level Understanding of Gene-Diet Interactions, pp. 125-142 [M Kussmann and PJ Stover, editors]. Chichester: Wiley.

42. Gaziano JM, Manson JE, Branch LG et al. (1995) A prospective study of consumption of carotenoids in fruits and vegetables and decreased cardiovascular mortality in the elderly. Ann Epidemiol 5, 255-260.

43. Oyebode O, Gordon-Dseagu V, Walker A et al. (2014) Fruit and vegetable consumption and all-cause, cancer and CVD mortality: analysis of health survey for England data. $J$ Epidemiol Community Health 68, 856-862.

44. Zhao G, Zhang R, Liu L et al. (2017) Different thermal drying methods affect the phenolic profiles, their bioaccessibility and antioxidant activity in Rhodomyrtus tomentosa (Ait.) Hassk berries. LWT - Food Sci Technol 79, 260-266.

45. Jovanovic-Malinovska R, Kuzmanova S \& Winkelhausen E (2014) Oligosaccharide profile in fruits and vegetables as sources of prebiotics and functional foods. Int J Food Prop 17, 949-965.

46. Alasalvar C \& Shahidi F (editors) (2013) Composition, phytochemicals, and beneficial health effects of dried fruits: an overview. In Dried Fruits: Phytochemicals and Health Effects, pp. 1-18. New York: John Wiley \& Sons, Inc.

47. Mandalari G, Bisignano C, Filocamo A et al. (2013) Bioaccessibility of pistachio polyphenols, xanthophylls, and tocopherols during simulated human digestion. Nutrition 29, 338-344.

48. Mudahar GS, Toledo RT, Floros JD et al. (1989) Optimization of carrot dehydration process using response surface methodology. J Food Sci 54, 714-719.

49. Shi J, Maguer ML, Kakuda Y et al. (1999) Lycopene degradation and isomerization in tomato dehydration. Food Res Int 32, 15-21.

50. Vinson JA, Zubik L, Bose P et al. (2005) Dried fruits: excellent in vitro and in vivo antioxidants. J Am Coll Nutr 24, 44-50.

51. US Department of Health and Human Services \& US Department of Agriculture (2015) 2015-2020 Dietary Guidelines for Americans, 8th ed. http://health.gov/ dietaryguidelines/2015/guidelines/ (accessed December 2017).

52. Lautenschlager L \& Smith C (2007) Understanding gardening and dietary habits among youth garden program participants using the Theory of Planned Behavior. Appetite 49, $122-130$.

53. Blanchard CM, Fisher J, Sparling PB et al. (2009) Understanding adherence to 5 servings of fruits and vegetables per day: a Theory of Planned Behavior perspective. $J$ Nutr Educ Behav 41, 3-10.

54. Kim K, Reicks D \& Sjoberg S (2003) Applying the Theory of Planned Behavior to predict dairy product consumption by older adults. J Nutr Educ Behav 35, 294-301.

55. Lee ST \& MaCleary K (2013) The relationship between perceived health, health attitude, and healthy offering for seniors at family restaurants. Cornell Hospit Q 54, 262-273.

56. Rah JH, Hasler CM, Painter JE et al. (2004) Applying the Theory of Planned Behavior to women's behavioral attitudes on and consumption of soy products. J Nutr Educ Behav 36, 238-244.

57. Jung SE, Santella M, Hermann C et al. (2018) Understanding college students' intention to consume fruits and vegetables: an application of the Model of Goal Directed Behavior. Int J Health Promot Educ 56, 211-225.

58. Yeh MC, Ickes SB, Lowenstien LM et al. (2008) Understanding barriers and facilitators of fruit and vegetable consumption among a diverse multi-ethnic population in the USA. Health Promot Int 23, 42-51.

59. May JK, Brady A, Van Offelen S et al. (2014) Simply good cooking: online curriculum for the interactive SNAPEd classroom. J Nutr Educ Behav 46, 85-87.

60. Adam M, Young-Wolff KC, Konar E et al. (2015) Massive open online nutrition and cooking course for improved eating behaviors and meal composition. Int J Behav Nutr Phys Act 12, 143

61. Carfora V, Caso D \& Conner M (2016) The role of self-identity in predicting fruit and vegetable intake. Appetite 106, 23-29.

62. Boomsma A (1985) Nonconvergence, improper solutions, and starting values in LISREL maximum likelihood estimation. Psychometrika 50, 229-242.

63. Muthén LK \& Muthén BO (2009) How to use a Monte Carlo study to decide on sample size and determine power. Struct Equ Modeling 9, 599-620. 